Case Report

\title{
Prenatal Diagnosis of $4 p$ and $4 q$ Subtelomeric Microdeletion in De Novo Ring Chromosome 4
}

\author{
Halit Akbas, ${ }^{1,2}$ Naci Cine, ${ }^{3}$ Mahmut Erdemoglu, ${ }^{4}$ Ahmet Engin Atay, ${ }^{5}$ \\ Selda Simsek, ${ }^{2}$ Aysegul Turkyilmaz, ${ }^{2}$ and Mehmet Fidanboy ${ }^{2}$ \\ ${ }^{1}$ Department of Medical Biology, Faculty of Medicine, Harran University, 63100 Sanliurfa, Turkey \\ ${ }^{2}$ Department of Medical Biology and Genetics, Faculty of Medicine, Dicle University, 21280 Diyarbakir, Turkey \\ ${ }^{3}$ Department of Medical Genetics, Faculty of Medicine, Kocaeli University, 41000 Kocaeli, Turkey \\ ${ }^{4}$ Department of Gynecology and Obstetrics, Faculty of Medicine, Dicle University, 21280 Diyarbakir, Turkey \\ ${ }^{5}$ Department of Internal Medicine, Bagcilar Education and Research Hospital, 34200 Istanbul, Turkey
}

Correspondence should be addressed to Halit Akbas; ehves3@gmail.com

Received 28 September 2013; Accepted 29 October 2013

Academic Editors: S. Z. A. Badawy and M. A. Osmanagaoglu

Copyright (C) 2013 Halit Akbas et al. This is an open access article distributed under the Creative Commons Attribution License, which permits unrestricted use, distribution, and reproduction in any medium, provided the original work is properly cited.

\begin{abstract}
Ring chromosomes are unusual abnormalities that are observed in prenatal diagnosis. A 23-year-old patient (gravida 1, para 0) referred for amniocentesis due to abnormal maternal serum screening result in the 16th week of second pregnancy. Cytogenetic analysis of cultured amniyotic fluid cells revealed out ring chromosome 4. Both maternal and paternal karyotypes were normal. Terminal deletion was observed in both $4 \mathrm{p}$ and $4 \mathrm{q}$ arms of ring chromosome 4 by fluorescence in situ hybridization (FISH). However deletion was not observed in the WHS critical region of both normal and ring chromosome 4 by an additional FISH study. These results were confirmed by means of array-CGH showing terminal deletions on $4 \mathrm{p} 16.3(130 \mathrm{~kb})$ and $4 \mathrm{q} 35.2(2.449 \mathrm{Mb})$. In the 21th week of pregnancy, no gross anomalia, except two weeks symmetric growth retardation, was present in the fetal ultrasonographic examination. According to our review of literature, this is the first prenatal case with $4 \mathrm{p}$ and $4 \mathrm{q}$ subtelomeric deletion of ring chromosome 4 without the involvement of WHS critical region. Our report describes the prenatal case with a ring chromosome 4 abnormality completely characterized by array-CGH which provided complementary data for genetic counseling of prenatal diagnosis.
\end{abstract}

\section{Introduction}

Autosomal ring chromosomes are uncommon cytogenetic aberrations in prenatal diagnosis. Estimated frequency ranges from $1 / 27000$ to $1 / 62000$ in consecutive newborn and prenatal diagnosis studies [1]. The classic mechanism of ring formation is breakage in both arms of a chromosome followed by fusion of the two broken arms and loss of the distal segments. Therefore, phenotypic abnormalities associated with partial deletions can be found among patients with ring chromosomes [2-4]. Cases with ring chromosome 4 share common clinical features, including severe mental and motor retardation, cleft lip and palate, low birth weight, and microcephaly [5]. Diagnosis of ring chromosomes and identifying deleted segment, which is rarely diagnosed in the prenatal period, is of critical information for genetic counselling.
In the present study, our aim was to determine whether ring chromosome leads to abnormality in the following weeks of pregnancy or in the postnatal period of fetus which has no gross anomalia in the second trimester of pregnancy, except growth retardation, and the second aim was to manage genetic counselling to family members. For this purpose, we performed classical cytogenetic, molecular cytogenetic (FISH), and array-CGH techniques in amniocentesis and chordosynthesis samples to establish whether any deletion exists in ring chromosome 4 with breakpoints of deleted segments and identify genes involving deletions.

\section{Case Report}

A 23-years-old patient with a history of a pregnancy resulted with abortus referred for amniocentesis due to abnormal 


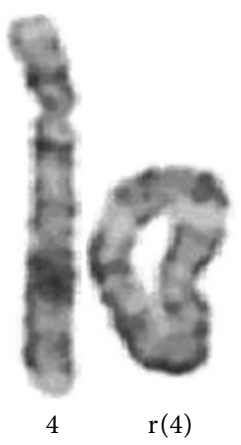

FIgure 1: Partial G-banded karyotype shows normal chromosome 4 and ring chromosome 4 .

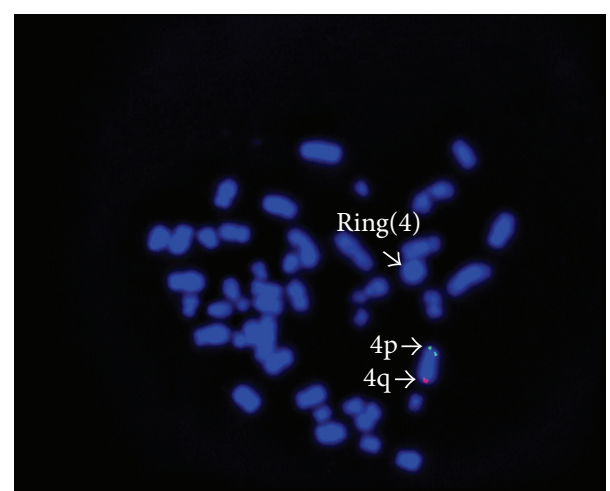

FIgURE 2: FISH study using a chromosome $4 \mathrm{p}$ specific subtelomeric probe (green signal) and a chromosome $4 \mathrm{q}$ specific subtelomeric probe (red signal) shows that subtelomeric $4 \mathrm{p}$ and $4 \mathrm{q}$ are deleted in ring chromosome 4.

maternal serum screening test in the 16 th week of the 2nd pregnancy. Down syndrome risk was 1,97 according to maternal serum screening test in the 12th week of pregnancy. Cytogenetic analysis of the cultured amniocytes using flask culture method revealed ring chromosome 4 [46,XX, r(4) [30 cells]] (Figure 1). To confirm the diagnosis, cytogenetic analysis of cord material obtained by cordocentesis was performed. Ring chromosome 4 was evident. Because parental caryotypes were normal, caryotype abnormality of case was considered de novo.

The ring chromosome 4 was characterized by FISH using the $4 \mathrm{p}$ and $4 \mathrm{q}$ specific subtelomeric probe (Chromoprobe Multiprobe-T System; Cytocell Ltd, UK). FISH study showed deletions at the subtelomeric regions of $4 \mathrm{p}$ and $4 \mathrm{q}$ on the ring chromosome 4 (Figure 2). WHS critical region probe with 4q subtelomere specific control probe was used to establish the diagnosis of deletion in the Wolf Hirschhorn critical region in the second FISH study (WHS Critical Region Probe, Cytocell). However deletion was not observed in WHS critical region of ring chromosome 4 (Figure 3).

Array-CGH was performed to determine breaking points and involved genes on terminal deletions of ring chromosome 4.

CytoSure microarray platform (Oxford Gene Technology) was used for aCGH analysis. This platform has approximately 44,000 oligonucleotide probes. The arrays were

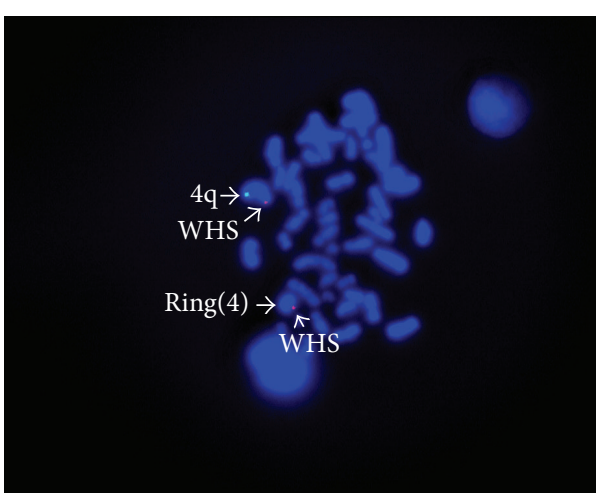

FIGURE 3: FISH study using a WHS critical region probe (red signal) and chromosome $4 \mathrm{q}$ subtelomere specific control probe (green signal) shows the presence of WHS critical region on both normal and ring chromosomes 4 .

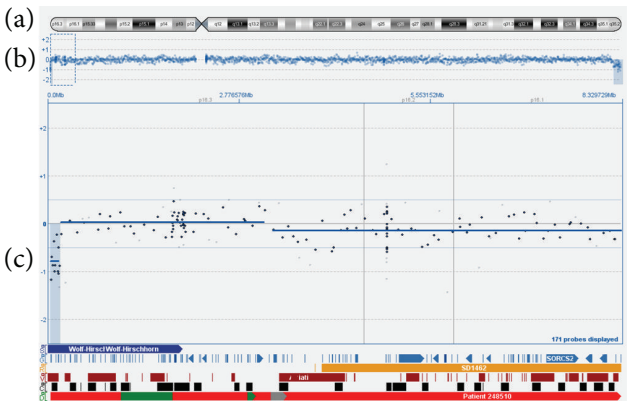

FIGURE 4: Array-CGH result of chromosome 4: 4 p16.3 $\rightarrow$ pter deletion. There are three icons from top to down in total (a)(c). (a) A diagram of chromosome 4. (b) A scatter plot of a copy number; each point represents the mean copy number calculated from consecutive 100 probe sets. The baseline in the middle indicates the normal copy number level. Upward deviation from the baseline indicates amplification and downward departure from the baseline represents deletion. (c) Enlarged form of 4 p16.3 $\rightarrow$ pter segment at (b) region; combed region represents copy number variants (CNV) that matches deleted segment.

scanned on an Agilent G2505B scanner and quantified using Agilent's Feature Extraction software. Data was then normalised using CytoSure visualisation software which uses a standard LOWESS method [6]. Subsequent to array$\mathrm{CGH}$, a deletion of $130 \mathrm{~Kb}$ involving 6 genes in $4 \mathrm{p} 16.3$ [arr 4p16.3(Start: 34021 - Stop: 164174xl)] and a second deletion of $2.449 \mathrm{Mb}$ involving 17 genes in $4 \mathrm{q} 35.2$ [arr 4q35.2(Start: 188713284 - Stop: 191162284x1)] were determined (Figures 4 and 5). The list of deleted genes was shown in Table 1. Deletion range in $4 \mathrm{p}$ determined by array-CGH (Start: 34021 - Stop: 164174) was out of range of FISH probe which was used for WHS critical region (Start: 1.894.975 - Stop: 2.117.567). Eventually, the results of FISH and array-CGH confirm each other.

In the 21th week of pregnancy, no gross anomalia, except 2 weeks symmetric growth retardation, existed in the fetal ultrasonographic examination. Parents were informed about the probable prenatal and postnatal complications of 
TABLE 1: Deletions and related genes of ring chromosome by Array-CGH.

\begin{tabular}{|c|c|c|}
\hline $\begin{array}{l}\text { Cytogenetic location of } \\
\text { deleted segments }\end{array}$ & Genes & $\begin{array}{l}\text { Bioinformatic data of deleted genes according to } \\
\text { genome database }\end{array}$ \\
\hline \multirow{6}{*}{$4 \mathrm{p} 16.3 \rightarrow$ pter } & $\underline{\text { ZNF595 }}$ & $\begin{array}{l}\text { Zinc finger protein } 595 \text { may be involved in } \\
\text { transcriptional regulation. Function: DNA binding, } \\
\text { metal ion binding. }\end{array}$ \\
\hline & $\underline{\text { ZNF718 }}$ & $\begin{array}{c}\text { Zinc finger protein } 718 \text { may be involved in } \\
\text { transcriptional regulation, regulation of } \\
\text { transcription. }\end{array}$ \\
\hline & $\underline{Z 95704.1}$ & $\begin{array}{l}\text { Zinc finger protein } 718 \text { may be involved in } \\
\text { transcriptional regulation. }\end{array}$ \\
\hline & $\underline{\mathrm{AC} 118278.4-2}$ & $\begin{array}{c}\text { Zinc finger protein } 718 \text { may be involved in } \\
\text { transcriptional regulation, regulation of } \\
\text { transcription. }\end{array}$ \\
\hline & $\underline{\mathrm{AC} 118278.4-1}$ & $\begin{array}{c}\text { Zinc finger protein } 718 \text { may be involved in } \\
\text { transcriptional regulation, regulation of } \\
\text { transcription. }\end{array}$ \\
\hline & $\underline{\mathrm{AC} 108475.5}$ & $\begin{array}{l}\text { Zinc finger protein 876: pseudogene, function: DNA } \\
\text { binding, metal ion binding. }\end{array}$ \\
\hline \multirow{17}{*}{$4 \mathrm{q} 35.2 \rightarrow$ qter } & AC093909.2: & Long intergenic nonprotein coding RNA 1060 \\
\hline & $\underline{\mathrm{AC} 097521.2-1:}$ & uncharacterized \\
\hline & AC097521.2-2: & uncharacterized \\
\hline & $\underline{\mathrm{AC} 115540.3}$ & ADAM metallopeptidase domain 20 pseudogene 3 . \\
\hline & $\underline{\mathrm{AC} 108073.3-1}$ & $\begin{array}{l}\text { ZFP42 zinc finger protein. Function: DNA binding, } \\
\text { metal ion binding. }\end{array}$ \\
\hline & $\underline{\mathrm{AC} 108073.3-2,}$ & $\begin{array}{l}\text { TRIML2: tripartite motif family-like 2. Function: } \\
\text { ligase activity. }\end{array}$ \\
\hline & $\underline{\mathrm{AC} 108073.3-3:}$ & $\begin{array}{l}\text { FAUP3: FBR-MuSV-associated ubiquitously } \\
\text { expressed (fox derived) pseudogene } 3 \text {. }\end{array}$ \\
\hline & $\underline{\mathrm{ZFP} 42}$ & $\begin{array}{l}\text { Zinc finger protein. Function: DNA binding, metal } \\
\text { ion binding. }\end{array}$ \\
\hline & $\underline{\text { TRIML2 }}$ & $\begin{array}{l}\text { Tripartite motif family-like 2. Function: igase } \\
\text { activity. }\end{array}$ \\
\hline & U6: & RNA; U6 small nuclear 1 \\
\hline & $\underline{\text { TRIML1, }}$ & $\begin{array}{l}\text { Tripartite motif family-like } 1 \text {. Function: ligase } \\
\text { activity, zinc ion binding. }\end{array}$ \\
\hline & $\underline{\text { HSP90AA4P, }}$ & $\begin{array}{l}\text { Heat shock protein } 90 \mathrm{kDa} \text { alpha (cytosolic), class A } \\
\text { member 4, pseudogene. } \\
\text { Function: unfolded protein binding, ATP binding. }\end{array}$ \\
\hline & $\underline{\mathrm{U} 1,}$ & small nuclear RNA. \\
\hline & AF250324.1-1, & uncharacterized \\
\hline & $\underline{\text { FRG1 }}$ & $\begin{array}{l}\text { FSHD region gene } 1 \text {. This gene is deleted in } \\
\text { facioscapulohumeral muscular dystrophy (FSHD). }\end{array}$ \\
\hline & TUBB4Q, & Tubulin, beta 7, pseudogene. \\
\hline & $\underline{\text { AF146191.1-2: }}$ & $\begin{array}{l}\text { FRG2: FSHD region gene } 2 \text {. This gene is related with } \\
\text { facioscapulohumeral muscular dystrophy (FSHD). }\end{array}$ \\
\hline
\end{tabular}

${ }^{*}$ http://www.ncbi.nlm.nih.gov/gene/.

subtelomeric deletion of $\mathrm{p}$ and $\mathrm{q}$ arms of chromosome 4 . However, parents denied to terminate pregnancy.

\section{Discussion}

In the present report, prenatal case with $4 \mathrm{p} 16.3$ and $4 \mathrm{q} 35.2$ subtelomeric deletion of ring chromosome 4 without the involvement of WHS critical region was diagnosed.
Ring chromosome 4 is an uncommon cytogenetic abnormality that has been rarely diagnosed in the prenatal stage. Up to now, three cases with prenatal diagnosis of ring chromosome 4 were reported in the English literature. In the first case, Sherer et al. reported a severely and symmetrically growth-retarded fetus with microcephaly, hypertelorism, and hypoplastic genitalia with a two-vessel umbilical cord, a characteristic "Greek warrior helmet" facial profile and clubfoot in 


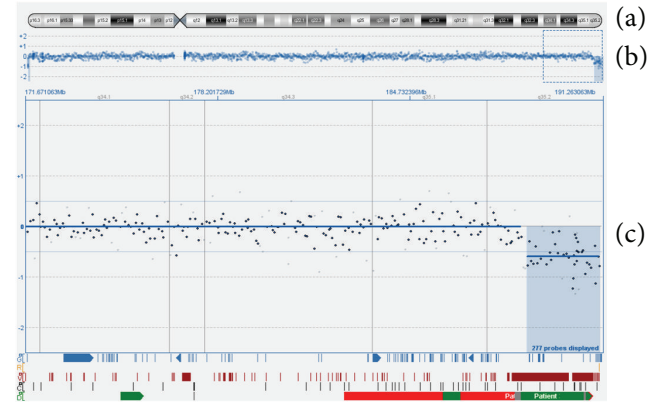

FIGURE 5: Array-CGH result of chromosome 4: $4 \mathrm{q} 35.2 \rightarrow$ qter deletion. There are three icons from top to down in total (a)(c). (a) A diagram of chromosome 4. (b) A scatter plot of a copy number; each point represents the mean copy number calculated from consecutive 100 probe sets. The baseline in the middle indicates the normal copy number level. Upward deviation from the baseline indicates amplification and downward departure from the baseline represents deletion. (c) Enlarged form of $4 \mathrm{q} 35.2 \rightarrow$ qter segment at (b) region; combed region represents copy number variants $(\mathrm{CNV})$ that matches deleted segment.

a 29th week fetus of ring chromosome 4 carrier with 4 p15 and $4 q 35$ deletions [7]. In the second case, Chen et al. reported a case with intrauterine growth retardation, increased nuchal translucency, and a suspected cardiac malformation in a 17th week fetus of ring chromosome 4 carrier with 4 p15.2 and $4 \mathrm{q} 35.2$ deletions [8]. The third case was a female fetus at the 21st week of gestation with ring chromosome 4 (p16;q33) which presented with further abnormalities, namely, cleft lip, left-sided diaphragmatic hernia with cardiac dextroposition, a single umbilical artery, and pathological uterine blood flow patterns [9]. In all of 3 cases, deletions involve larger segments than those in our case and deleted 4 p segment involved WHS critical region that was responsible from the development of Wolf-Hirschorn Syndrome. In contrast, 4p16.3 deletion in our case involves a small segment of $130 \mathrm{~kb}$ and does not involve WHS critical region. Fetal ultrasonographic examination pointed out growth retardation of two weeks without an accompanying abnormality. This may be related to absence of deletion in the WHS critical region and shortness of deleted segments than previous three cases.

Among published cases with 4 p16 deletions, South et al. reported a case of ring 4 with $1.27-1.46 \mathrm{Mb}$ deletion at $4 \mathrm{p} 16.3$ presented with significant postnatal growth retardation, mild developmental retardation, and nutritional disturbances. In addition to abnormalities of the first case, the second reported that a case exhibited terminal $4 \mathrm{p}$ microdeletion of approximately $1.78 \mathrm{Mb}$ caused complex seizure disorder. No deletion was observed at WHS region in both cases [10]. Khonsari et al. reported a case with deletion of $300 \mathrm{~kb}$ from telomere presented with multiple vascular malformations, unilateral syndactyly, and bilateral macrodactyly in the postnatal period [11]. Blackett et al. reported another case of ring chromosome 4 with a deletion of $145 \mathrm{~kb}$ at $4 \mathrm{p} 16$ that has mild growth retardation, deafness, short stature, obesity, and early onset of type 2 diabetes [12]. Furthermore, small $4 \mathrm{p}$ deletions located approximately $100-300 \mathrm{~kb}$ from $4 \mathrm{p}$ ter are reported without phenotypic modification [13]. Another case had subtelomeric 4q35.2 deletion that encompasses approximately $3 \mathrm{Mb}$ with comorbid schizoaffective disorder and mental retardation [14]. It is possible that our patient may experience similar abnomalies in the later periods of pregnancy and postnatal period.

In the present case, genes that encode 6 zinc finger protein exist on deleted segment of $130 \mathrm{~kb}$ at $4 \mathrm{p} 16.3$ as shown in Table 1. To the best of our knowledge, no anomalia that is related to these genes existed in the literature. On the other hand, seventeen genes exist on deleted segment of $2.449 \mathrm{Mb}$ at $4 \mathrm{q} 35.2$. Among the genes that were shown in Table 1, only FRG1 and FRG2 genes were considered to relate with facioscapulohumeral muscular dystrophy [15]. Hemizygosity of deleted 23 genes on $4 \mathrm{p}$ and $4 \mathrm{q}$ of ring chromosome have risk of clinical pathologies at the postnatal period. Parents were informed about the risk of anomalies.

According to our knowledge, this is the first de novo ring chromosome 4 case with $4 \mathrm{p}$ and $4 \mathrm{q}$ subtelomeric deletion without deletion of WHS critical region and that had no fetal anomalia except intrauterine growth retardation determined by second trimester fetal ultrasonographic examination. In the light of literature, genetic counselling was performed to family members by considering genes on deleted segments. The role of FISH and array-CGH on genetic diagnosis and phenotypic correlation in the prenatal evaluation is confirmed.

\section{Acknowledgment}

The authors thank the family for their interest and support for the study.

\section{References}

[1] H. E. Wyandt, "Ring autosomes: identification, familial transmission, causes of phenotypic effects and in vitro mosaicism," in The Cytogenetics of Mammalian Autosomal Rearrangements, A. Daniel, Ed., pp. 667-696, Alan R. Liss, New York, NY, USA, 1988.

[2] G. Kosztolányi, "Ring chromosome 4: wolf syndrome and unspecified developmental anomalies," Acta Paediatrica Hungarica, vol. 26, pp. 157-165, 1985.

[3] J. R. Sawyer, J. L. Lukacs, S. J. Hassed, G. L. Arnold, H. F. Mitchell, and M. Muenke, "Subband deletion of 7q36. 3 in a patient with ring chromosome 7: association with holoprosencephaly," American Journal of Medical Genetics, vol. 65, pp. 113116,1996

[4] L. Rodriguez, A. Sanchis, A. Villa et al., "Ring chromosome 7 and sacral agenesis," American Journal of Medical Genetics, vol. 94, pp. 52-58, 2000.

[5] S. Balci, Ö. Engiz, D. Aktaş et al., "Ring chromosome 4 and Wolf-Hirschhorn syndrome (WHS) in a child with multiple anomalies," American Journal of Medical Genetics, vol. 140, no. 6, pp. 628-632, 2006.

[6] S. Cleveland William, "Robust locally weighted regression and smoothing scatterplots," Journal of the American Statistical Association, vol. 74, pp. 829-836, 1979. 
[7] D. M. Sherer, Y. G. Shah, N. Wang, L. A. Metlay, and J. R. Woods Jr., "Prenatal diagnosis and subsequent management of a fetus with a 46XY r(4)(p15-q35) karyotype," American Journal of Perinatology, vol. 8, no. 1, pp. 53-55, 1991.

[8] C. P. Chen, C. Y. Hsu, C. Y. Tzen et al., "Prenatal diagnosis of mosaic ring chromosome 4," Prenatal Diagnosis, vol. 27, no. 5, pp. 485-487, 2007.

[9] A. Kocks, S. Endele, R. Heller et al., "Partial deletion of $4 \mathrm{p}$ and $4 \mathrm{q}$ in a fetus with ring chromosome 4: phenotype and molecular mapping of the breakpoints," Journal of Medical Genetics, vol. 39, no. 5, article e23, 2002.

[10] S. T. South, S. B. Bleyl, and J. C. Carey, "Two unique patients with novel microdeletions in $4 \mathrm{p} 16.3$ that exclude the WHS critical regions: implications for critical region designation," American Journal of Medical Genetics A, vol. 143, no. 18, pp. 2137-2142, 2007.

[11] R. H. Khonsari, K. M. Blechman, J. Michaels et al., "Vascular malformations and upper extremity anomalies associated with a subtelomeric microdeletion of chromosome 4p," Clinical Dysmorphology, vol. 17, no. 3, pp. 193-194, 2008.

[12] P. R. Blackett, S. Li, and J. J. Mulvihill, "Ring chromosome 4 in a patient with early onset type 2 diabetes, deafness, and developmental delay," American Journal of Medical Genetics, vol. 137, no. 2, pp. 213-216, 2005.

[13] G. Van Buggenhout, C. Melotte, B. Dutta et al., "Mild WolfHirschhorn syndrome: micro-array CGH analysis of atypical 4 p16.3 deletions enables refinement of the genotype-phenotype map," Journal of Medical Genetics, vol. 41, no. 9, pp. 691-698, 2004.

[14] B. S. Pickard, E. J. Hollox, M. P. Malloy et al., "A 4q35.2 subtelomeric deletion identified in a screen of patients with co-morbid psychiatric illness and mental retardation," $B M C$ Medical Genetics, vol. 5, article 21, 2004.

[15] M. L. Hanel, R. D. Wuebbles, and P. L. Jones, "Muscular dystrophy candidate gene FRG1 is critical for muscle development," Developmental Dynamics, vol. 238, no. 6, pp. 1502-1512, 2009. 


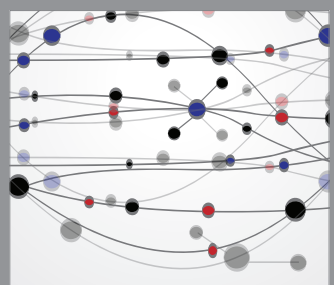

The Scientific World Journal
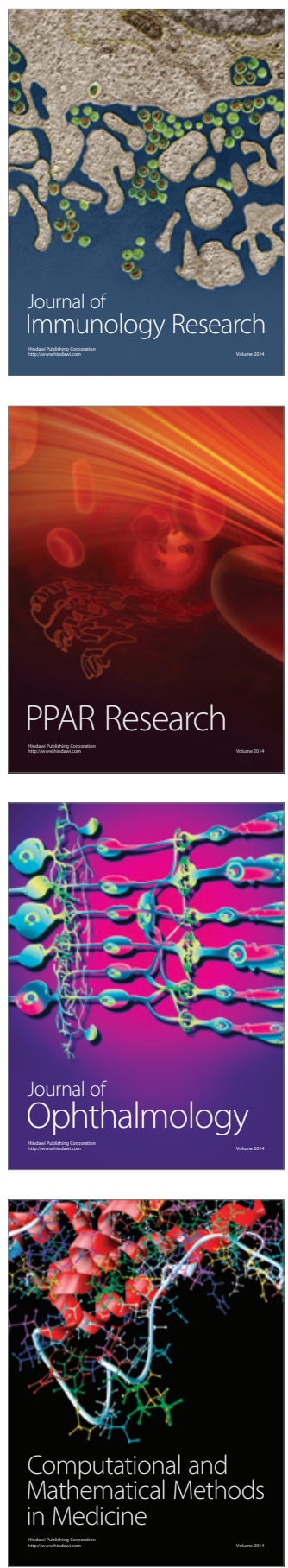

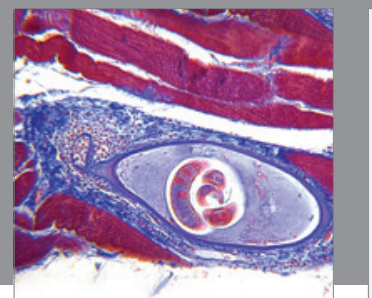

Gastroenterology

Research and Practice
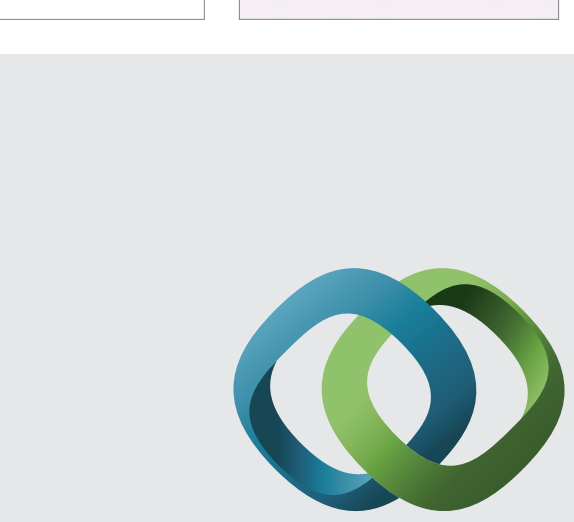

\section{Hindawi}

Submit your manuscripts at

http://www.hindawi.com
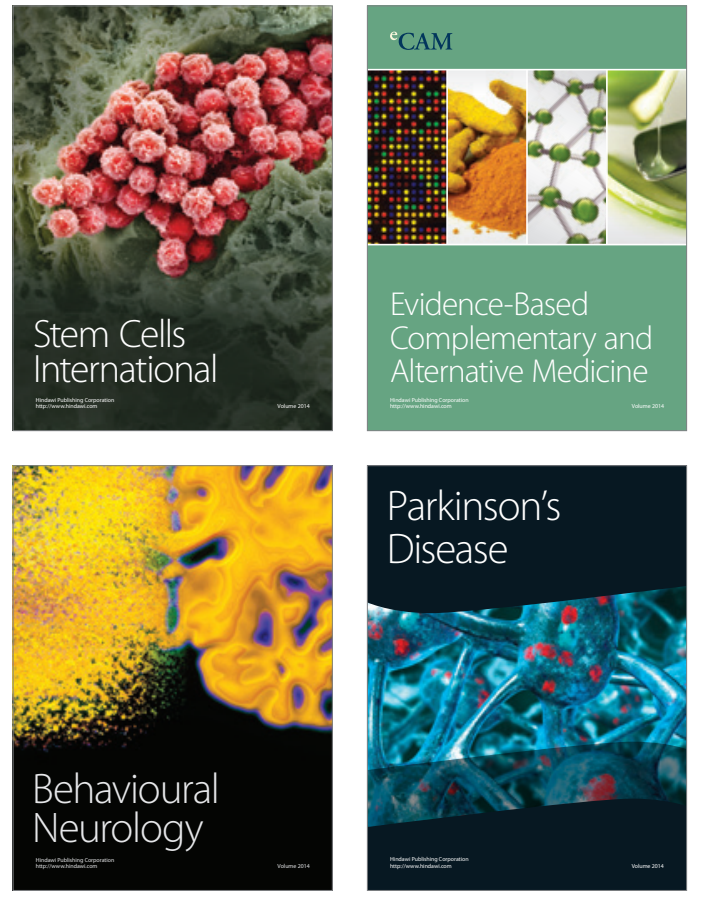
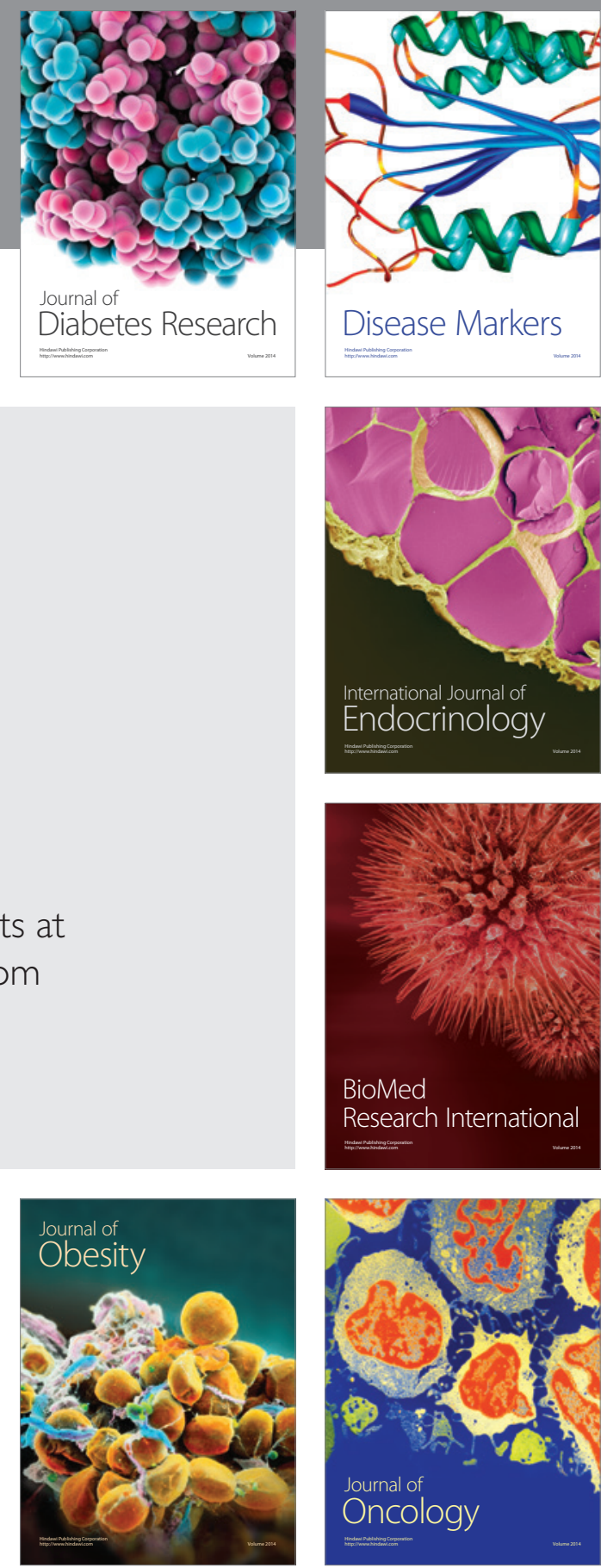

Disease Markers
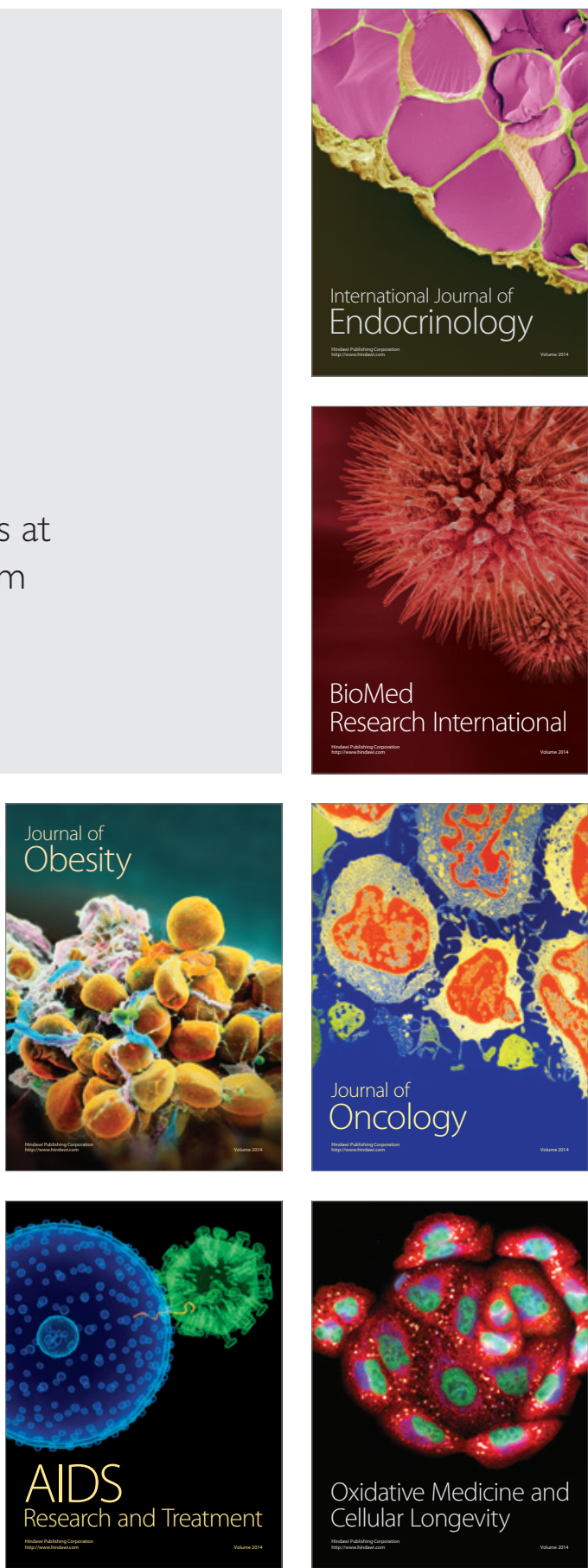